\title{
The philosophy of paediatric teaching: An interview with Dr Nikolaos Myriokefalitakis, former Clinical Director of the 'Penteli' Children's Hospital in Athens (Greece)
}

\author{
IOANNIS N. MAMMAS and DEMETRIOS A. SPANDIDOS \\ Department of Clinical Virology, School of Medicine, University of Crete, Heraklion 71003, Greece
}

Received June 22, 2018; Accepted July 23, 2018

DOI: $10.3892 /$ etm.2018.6546

\begin{abstract}
Dr Nikolaos Myriokefalitakis, one of the most experienced paediatricians in the city of Athens, Greece, has worked as a consultant paediatrician at the 'P. \& A. Kyriakou' Children's Hospital for more than 25 years, while during the 2004-2011 period, he was the clinical director of the 1st Paediatric Department of the 'Penteli' Children's Hospital. Under his leadership, in 2008, his department was renovated by 'Stavros Niarchos Foundation' and was organised as one of the most modern and exemplary national paediatric departments in Greece. Having the title of the 'teacher in paediatrics' by his junior Greek colleagues, he supports that clinical experience obtained through ward-based bedside teaching is the fundamental principle of paediatric teaching. He notes that paediatric diagnosis is performed thorough medical history and detailed physical examination of the patient and it is rarely established with the help of laboratory, common or specialised, investigations. According to Dr Myriokefalitakis, a modern paediatric department cannot function 'in a vacuum', but requires technological support, adequate medical and nursing personnel and team-working between paediatricians and experts on paediatric subspecialties and other basic specialties. He accepts that the current financial crisis in Greece has clearly affected negatively the clinical practice of primary as well as hospital-based paediatric care, while he regrets to note that as the years go by, physicians become more obsessed with defense medicine and technology. He suggests that it is necessary to distinguish paediatric virology from virology and he ends up encouraging the improvement of paediatric training in Greece highlighting the basic need to 'train the trainers' in medical education.
\end{abstract}

Correspondence to: Professor Demetrios A. Spandidos, Department of Clinical Virology, School of Medicine, University of Crete, Heraklion 71003, Greece

E-mail: spandidos@spandidos.gr

Key words: paediatrics, teaching, paediatric training programme, influenza, Kawasaki disease, paediatric virology, workshop, 'Penteli' Children's Hospital, Dr Nikolaos Myriokefalitakis

\section{Contents}

1. Introduction

2. Questions and Answers

\section{Introduction}

Dr Nikolaos Myriokefalitakis (Fig. 1) was born in Rethymnon on the island of Crete in Greece, where he received his elementary and secondary education. He studied medicine at the Medical School of the University in Athens, where he entered in 1965. He performed his paediatric training at the 2nd Paediatric Department of the University of Athens at 'P. \& A. Kyriakou' Children's Hospital in Athens from 1976 to 1978. In 1979 he completed his PhD entitled 'Patient compliance with medical instructions' under the supervision of Professor Constantinos Papadatos, Professor of Paediatrics at the University of Athens and founder of the 2nd Paediatric Department of the University of Athens at 'P. \& A. Kyriakou' Children's Hospital (1). The person, who helped him to establish his career in paediatrics and had catalytic influence on his way of clinical thinking, was Professor Constantinos Sinaniotis, initially consultant paediatrician, and finally clinical director for several years of the 2nd Paediatric Department of the University of Athens.

Dr Myriokefalitakis worked as a consultant paediatrician for more than 25 years at the 2nd Paediatric Department of the University of Athens at the 'P. \& A. Kyriakou' Children's Hospital. This is one of the two central paediatric hospitals of the city of Athens, with a large number of children's attendances and admissions and an incredible variety of medical cases from the whole spectrum of children's pathology. During this period, he was actively involved in the teaching of the medical students of University of Athens, paediatric trainees, nurses and nursing students on the ward. In 2004, he was elected as the clinical director of the 1st Paediatric Department of the 'Penteli' Children's Hospital in Athens, where he worked until 2011. His clinical and educational work at this department was recognised by all his colleagues as state-of-the-art. During the last 3 years of his career, he was appointed as a member of the Examinations Committee for the paediatric specialty in the prefecture of Attica, the largest prefecture in Greece. 
To date, Dr Myriokefalitakis is considered as one of the most experienced paediatricians in the city of Athens. He has been a member of the Board of Directors of the Hellenic Paediatric Society (HPS) for several years, while he has been its vice-president from March, 2013 to June, 2014. His publications in PubMed (2-8) represent only a limited part of his rich clinical and educational input in paediatrics. He has also developed a wealth of action in the teaching, writing and translation field of paediatric textbooks (9-11). He has been one of the principle reviewers of the Greek paediatric journal 'Paidiatriki', while due to his mastery of Greek language he has been the language editor of several Greek paediatric articles and textbooks, including the book Clinical Paediatrics by Professor Andreas Constantopoulos, Professor of Paediatrics at the University of Athens (12). To date, Dr Myriokefalitakis has advised and supported the Paediatric Virology Study Group (PVSG) and has been member of its academic advisory board. Recently, he was awarded by the PVSG with the '2016 Paediatric Virology Award in Paediatrics' for his exceptional clinical and teaching contribution in the management of paediatric viral infections in Greece.

\section{Questions and Answers}

Question: Dr Nikolaos Myriokefalitakis, how important is ward-based bedside teaching of paediatric trainees on the diagnosis of paediatric viral infections?

Answer: Clinical experience is obtained through bedside teaching, next to the patient. This is the fundamental principle of paediatric teaching. In the amphitheater, theoretical knowledge, necessary though, is offered. However, clinical skills are shaped on the ward, inside the patient's room and this is where a successful paediatric teaching should be performed. This principle seems not to have changed over time. Aristotle (Stagira, Chalkidiki, 384 BC-Chalkida, Island of Euboea, 322 BC), the most significant ancient Greek philosopher, writes in his book entitled Nikomachean Ethics (13) that "we do not see doctors becoming expert physicians only from studying

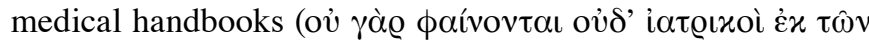

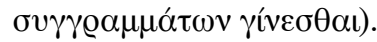

It has also always been a common, stereotyped knowledge that good medical history is the necessary basis for diagnosis. Repeated reminders become tedious, but they are right, and whoever overlooks this, will be exposed. If a physician, experienced or younger, has performed a diagnosis before a thorough medical history and detailed physical examination of the patient, he or she will often fail. In paediatrics, diagnosis rarely is established with the help of laboratory common investigations and, more rarely, with specialised ones. I remember for example, children with measles, who had been admitted to the ward in order to investigate their 'fever of unknown origin', sometimes even when the rash was present!

Question: Recently, paediatric virology has been proposed by our PVSG as a new candidate of paediatric subspecialisation (14). How possible do you believe that this scientific field will be officially recognised in the future?

Answer: Nowadays, the volume of knowledge in medicine is so great that, today, not only specialties, but also subspecialties are necessary. The peculiarities of paediatric virology are

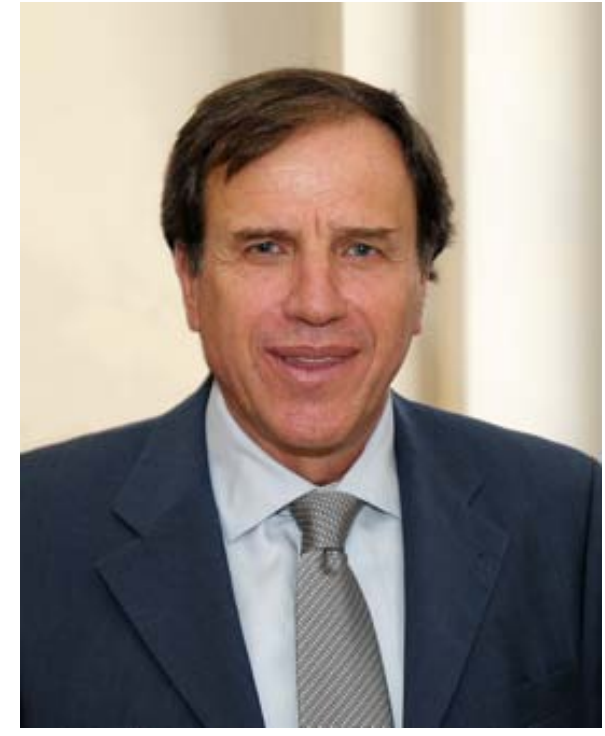

Figure 1. Dr Nikolaos Myriokefalitakis, former Clinical Director of the 1st Paediatric Department of the 'Penteli' Children's Hospital in Athens and Vice-President of the Hellenic Paediatric Society (HPS).

many; in my opinion, it is necessary to distinguish it from virology.

Question: You have organised as a clinical director the 1st Paediatric Department of the 'Penteli' Children's Hospital, one of the most modern and exemplary paediatric departments in Greece. How did you manage this? What was the key of your success?

Answer: In my opinion, your term 'modern and exemplary paediatric department' is inordinate, not for the sake of moderation, but because this characterisation is sadly far away from reality. A modern department cannot function 'in a vacuum'. There is a need for a thorough technological support, adequate medical and nursing staff, as well as the input of experts on basic specialties and paediatric subspecialties; these conditions do not all exist. In the 1st Paediatric Department of the 'Penteli' Children's Hospital, we tried to deal with common and rare paediatric problems with realism and rationality, but also on the basis of current international guidelines. However, this logical and self-evident approach presents great difficulties in its implementation. It requires knowledge, experience and, above all, good 'medical philosophy'. I believe that this is what it was appreciated by my younger colleagues, who have worked with me during these years; and even the fact that I tried to transport all the knowledge and experience I had gained all the years of my clinical practice in the hospital to them, without sparing and selfishness.

Question: In 2008, the 1st Paediatric Department of the 'Penteli' Children's Hospital was renovated by 'Stavros Niarchos Foundation'. How difficult is for private initiative to support the national health system in Greece?

Answer: The donation by 'Stavros Niarchos Foundation' for the renovation of the 1st Paediatric Department, which was in poor condition, was certainly a great success and it brought me great joy and satisfaction. But making use of this donation was a painful experience for me. Since there was no respon- 
sible and specialised public representative to undertake this task, I had to coordinate contractors, architects, engineers, craftsmen, take on the role of designer, and so on. At the end, the result was good, but it could have been better and less stressful. It goes without saying that private initiative cannot substitute for the official state, although it often acts as a relief.

Question: Since 2010, Greece faces a continuous financial crisis, which has also impact on paediatric health. How has this crisis impaired your clinical work?

Answer: The financial crisis has clearly affected negatively the clinical practice of paediatric primary care and even more than it seems at first sight. Many parents are unable to pay for a private practice paediatrician and they attend national health care units including tertiary paediatric national hospitals, which regularly become overcrowded. Despite this is free-of-charge, this causes an enormous work-force to the paediatric experts in the tertiary centres, who become exhausted dealing with primary health care issues. Parents also choose not to vaccinate their children according to the national vaccination programme, because they are uninsured and need to pay for their vaccines. Other parents are directed to a private practice paediatrician only when there is a serious need for their children, such as an acute infectious disease, which may require hospital admission, leaving aside developmental and preventative medicine.

Question: Hospital-based paediatrics or community paediatrics? Which one do you enjoy it most?

Answer: The paediatrician's role is different in the hospital compared to the community. In both cases, of course, it is very important. Hospital-based medicine was closer to my scientific interests and my personality, so the choice of my hospital-based career was an one-way route. During the last few years, I have been dealing with community paediatrics; I find that it has its own charm. You rarely need to solve medical puzzles, but the proper guidance of children and their families is indeed of paramount importance.

Question: Our article on noroviruses published in the Italian paediatric journal Minerva Pediatrica reported for the first time in Greece the rates of hospital-based norovirus infections in relation to rotavirus infections (2). How necessary is indeed vaccination against rotavirus?

Answer: The modern western way of life imposes early childhood closeness at the kindergarten and consequently increased morbidity by pathogens that infect that age. Rotaviruses are clearly included in these pathogens and therefore vaccination of children against them is expected to protect them and their families from suffering. In this sense vaccination against rotaviruses is very useful. In advanced western countries of course, the possibility of care is usually immediate, so severe dehydration problems or life-threatening complications, such as intussusception, are rarely encountered.

Question: Idiopathic thrombocytopenic purpura (ITP) and $\mathrm{A} / \mathrm{H} 1 \mathrm{H} 1$ influenza infection; this case report entitled 'Thrombocytic thrombocytopenic purpura in a child with A/H1N1 influenza infection' was published in the Journal of Clinical Virology in June 2011 (5). This report described for the first time in the literature ITP in an influenza A/H1N1-infected child. How many times in your career did you face rare cases or complications not described in the literature?

Answer: Certainly there are a few, but when there is no direct recording, memory is unfortunately, after some years, leveling. A/H1N1 influenza induced ITP was a good example. However, as the word says that they are rare, it is more appropriate to say that they are not mentioned in the accessible literature, because most of the times they have come back and somewhere in the world have been published.

Question: Vaccination rates against influenza among health professionals remain low. Vaccination of paediatric and allied health professionals is essential to ensure that devastating public health events, such as the 1918 Spanish flu outbreak, are not repeated (15). How could we increase the current low percentages described among hospital-based colleagues?

Answer: Continuous medical education, which aims to keep paediatric health professionals up-to-date, is always the key to increasing vaccination rates; so it also applies to the promotion of vaccination rates against influenza. Health professionals usually appear and paradoxically very pale or even negative for their vaccination against influenza. I believe that only if the Public Health Services believe vaccination against influenza is necessary, and this vaccination is a prerequisite for being able to work in public or private health practice, this will become universal.

Question: I would like your comments on the recently increasing 'anti-vaccination movement'. How dangerous is this really? How do you believe that parental hesitancy towards vaccinations should be managed by the paediatric health professionals?

Answer: The so-called 'anti-vaccination movement' has been added to the causes that reduce the success of the current vaccination programme. Parents usually evaluate their paediatrician's opinion positively. Thus, if the paediatrician dedicates additional time to inform them, they will be finally convinced about the necessity of vaccinations. I am impressed by how often parents are unaware of the risks of natural disease in the case of non-vaccination, as well as the effects of lack of herd immunity. In most cases, conversation in mild way with persuasion, without excuses and censures, reverses the situation and parents complete the vaccination of their children.

Question: During yourclinicalexperience at the 'P.\&A.Kyriakou' and the 'Penteli' Children's Hospital you have diagnosed and managed several children with Kawasaki disease (KD). In one case, I remember you on the ward commenting on the possibility of the viral aetiology of KD. Since then, there have been several epidemiological studies, which have supported the concept of an infectious trigger - possibly viral - in a genetically susceptible children's population. Despite these studies, KD remains a disease of unknown cause. Is KD a viral-induced disease?

Answer: KD usually affects the first childhood and is due to vasculitis of the middle vessels. Its significance lies in its ability to create aneurysms in the coronary vessels and thus thrombosis and infarction. Its aetiology remains unknown, but it is thought to be an unexpected immune response to some 
external, potentially infectious, cause in genetically defined children; its prevalence is 25 times higher in the Far East countries than in Western countries. To date, research has not yet managed to link KD to a specific infectious cause, despite ongoing efforts (retroviruses, Epstein-Barr virus, coronaviruses, staphylococcal and streptococcal antigens, e.t.c.). In my opinion, viruses remain most likely the infectious cause of KD.

Question: All these years, your junior colleagues, who had the chance to work with you in the 'Penteli' Children's Hospital, feel very proud that you were their teacher in paediatrics. What would be your advice to new paediatricians, nowadays, in Greece?

Answer: When your younger colleagues call you 'teacher', this is the greatest honour and recognition. Personally, I think I have tried, as much as possible, to do just my job. I regret to note that as the years go by, physicians become more obsessed with defense medicine and technology. Technological achievements have indeed provided the physician with immeasurable help and basically have changed medicine as it was known just a few decades ago. However, its unobjectionable use without a specific diagnostic goal does not necessarily lead to the solution of the clinical problems and simply afflicts the patient, burdening family's as well as healthcare system's budget. Today, as in the past, it is essential that the clinical practice should be targeted on the basis of medical history and physical examination. The most probable diagnosis, or even the most probable ones, should be investigated in detail; not any unlikely disease should be established at the beginning of the differential diagnosis. The approach of the patient's problem should be progressive, as long as it is physically possible, and then the technology will be allied rather than dynastic.

Question: And our last question. Over the past years, you have been examiner at the paediatric specialty examinations in Athens, Greece. How paediatric training could be improved in Greece?

Answer: Much has to be done. There are several ideas and proposals. Their implementation, though, does not allow great optimism. The basic need is summarised in the phrase 'train the trainers'. How many of us, who train our new colleagues, are eligible for this mission? There are also paediatric departments that are under-functioning and totally inadequately staffed; in these departments new colleagues are trained and in some cases this training represents all the period of their specialty training. In addition, almost all departments, small or larger, are expected to educate a number of paediatricians disproportionately to their educational abilities; without any doubt this is a further negative factor. Training in subspecialised departments of paediatrics (e.g., neonatology, paediatric neurology, developmental medicine e.t.c.) is useful and necessary. However, to be effective, there must be specific training programmes in these departments, and trainees should not be just observers.

Question: Thank you very much for your support, your valuable advice and your exceptional paediatric teaching all these years.

\section{References}

1. Myriokefalitakis N: Patient compliance with medical instructions (Doctoral Thesis). 2nd Paediatric Department, University of Athens, Athens, 1979 (In Greek).

2. Mammas IN, Koutsaftiki C, Nika E, Vagia F, Voyatzi A Spandidos DA, Theodoridou $\mathrm{M}$ and Myriokefalitakis N: Prospective study of human norovirus infection in children with acute gastroenteritis in Greece. Minerva Pediatr 64: 333-339, 2012.

3. Mammas IN, Koutsaftiki C, Nika E, Vagia F, Zaravinos A, Priftis KN, Voyatzi A, Theodoridou M, Myriokefalitakis N and Spandidos DA: Detection of human metapneumovirus in infants with acute respiratory tract infection. Mol Med Rep 4: 267-271, 2011.

4. Mammas IN, Zaravinos A, Sourvinos G, Myriokefalitakis N, Theodoridou M and Spandidos DA: Can 'high-risk' human papillomaviruses (HPVs) be detected in human breast milk? Acta Paediatr 100: 705-707, 2011.

5. Mammas IN, Koutsaftiki C, Papantzimas K, Symeonoglou Z, Koussouri M, Theodoridou M and Myriokefalitakis N: Thrombocytic thrombocytopenic purpura in a child with A/ 1N1 influenza infection. J Clin Virol 51: 146-147, 2011.

6. Mammas IN, Koutsaftiki C, Tapaki-Papadopoulou G and Myriokefalitakis N: Pneumothorax in a child with pulmonary blastoma. J Pediatr 159: 162, 2011.

7. Mammas IN,KoutsaftikiC, Theodoridou Mand Myriokefalitakis N: Vaccination coverage of Greek paediatric healthcare workers against seasonal and A/H1N1 influenza. Acta Paediatr 99: 1114-1115, 2010.

8. Mammas I, Koutsaftiki C, Tapaki-Papadopoulou G and Myriokefalitakis N: Respiratory syncytial virus (RSV) bronchiolitis and excessive thrombocytosis. Acta Paediatr 99: 489-490, 2010.

9. Hay WW Jr, Levin MJ, Sondheimer JM and Deterding RR: Current Diagnosis and Treatment Pediatrics. 19th edition. McGraw Hill LANGE, Columbus, OH, 2009.

10. Merenstein GB, Kaplan DW and Rosenberg AA: Handbook of Pediatrics. 16th edition. New York, NY, 1991.

11. Milner RDG and Herber SM: Diagnostic Picture Tests in Pediatrics. 2nd edition. Wolfe Medical Publications Ltd. London, 1990.

12. Constantopoulos A: Basic Paediatrics. Medical Editions 'Zita', Athens: 2006-2007 (In Greek).

13. Aristotle, Apanta 9. Cactus, Athens, 1993. Aristotle. Nikomachean Ethics 3 (Ethica Nikomachia 3) (In Greek).

14. Mammas IN, Greenough A, Theodoridou M and Spandidos DA: Paediatric Virology: A new paediatric subspecialty? A proposal at the Workshop on Paediatric Virology, Athens, October 10, 2015. Exp Ther Med 11: 3-5, 2016.

15. Mammas IN, Theodoridou M and Spandidos DA: The 1918 Spanish flu outbreak that devastated a Greek island underlines past lessons that must never be forgotten. Acta Paediatr: Mar 31, 2018 (Epub ahead of print). doi: 10.1111/apa.14351.

This work is licensed under a Creative Commons Attribution-NonCommercial-NoDerivatives 4.0 International (CC BY-NC-ND 4.0) License. 